The main indication for MRI was headache waking at night $(16 \%)$ and an atypical headache (16\%). 32\% of patients had a previous MRI either for a different indication or done by the referring hospital prior to headache clinic.

Outcomes were positive with $71 \%$ of patients symptoms improving or completely resolving. $28 \%$ of patients had no improvement in symptoms. The most common treatments were Sumatriptan (43\% of patients) and Ibuprofen (26\% of patients), $21 \%$ of patients were medication free at the last appointment.

Conclusion Management of headache in children in our specialist tertiary clinic shows largely positive outcomes in improvement of symptoms. MRI was requested for majority of patients with no serious pathology identified in any patients. We suggest that while MRI is a useful tool, careful assessment and management of the symptoms may be able to avoid unnecessary investigations in majority some patients and improve their symptoms.

\section{G328(P) RISK OF TRANSVERSE MYELITIS FOLLOWING ZIKA VIRUS INFECTION}

${ }^{1} \mathrm{G}$ Oligbu, ${ }^{2} \mathrm{M}$ Fallaha, ${ }^{2} \mathrm{~L}$ Pay, ${ }^{3} \mathrm{~L}$ Ahmed, ${ }^{4} \mathrm{~A}$ Adepoju. ${ }^{7}$ Paediatric Infectious Diseases Research Group, Institute for Infection and Immunity, St George's, University of London, UK, St George's, University of London, UK; ${ }^{2}$ Department of Paediatrics, Imperial College London, UK; ${ }^{3}$ Department of Paediatrics, Northwick Park Hospital, London, UK; ${ }^{4}$ Department of Paediatrics and Child Public Health, University College Hospital, Ibadan, Nigeria

\subsection{6/archdischild-2018-rcpch.318}

Introduction Transverse myelitis (TM) is a neurological disorder causing acute cord injury as a result of acute inflammation, and it is often associated with infectious or autoimmune disease. $20 \%$ of all cases of TM occur in children.

Since 2015, an outbreak of Zika Virus infection (ZiKV) has been reported in over 30 countries. Emerging evidence suggest $\mathrm{ZikV}$ causes a spectrum of neurologic diseases. However, its association with TM, especially in children, is not well described.

Methods We undertook a systematic review of the English literature published from 1947 to August 2017 to evaluate the risk factors, distribution, pathogenesis, clinical presentation, management and outcomes of TM following Zika virus infection. Data sources included MEDLINE, EMBASE, Cochrane library, and references within identified articles. We also searched the papers using the ISI web of knowledge, to identify relevant articles and conference proceedings.

Results We identified 102 potential studies, of which 9 were duplicates and 89 were excluded on the basis of title and abstracts. Of the 4 eligible studies [5-8], there were 6275 with suspected $\mathrm{ZiKV}$ in all age groups. 695 cases were confirmed ZiKV either by RT-PCR in plasma, CSF and urine, ELIZA or MRI while excluding other aetiologies. There were $11(1.6 \%)$ cases of TM. Among 3 studies reporting clinical characteristics and outcome, the mean age was 23 years (Range $15-43)$ and $63 \%(n=5 / 8)$ of cases were male. $40 \%$ $(n=4 / 10)$ required admission to the ITU, with no reported case fatality.

Conclusions and clinical implications

Complications from ZiKV, although uncommon, may be severe. With international spread, clinicians need to be aware that $\mathrm{ZiKV}$ may be associated with TM. As only $10 \%$ of cases were children, standardising the collection and reporting for individual cases across regions and countries would further allow meaningful analysis of the data collected, enabling monitoring of trends over time.

\section{G329(P) RISK OF SEIZURE FOLLOWING ZIKA VIRUS INFECTION IN CHILDREN}

${ }^{1} \mathrm{~L}$ Pay, ${ }^{2} \mathrm{O}$ Oligbu, ${ }^{1} \mathrm{M}$ Fallaha, ${ }^{3} \mathrm{~L}$ Ahmed, ${ }^{4} \mathrm{P}$ Saroey, ${ }^{5} \mathrm{G}$ Oligbu. ${ }^{1}$ Department of Paediatrics, Imperial College London, UK; ${ }^{2}$ Accident and Emergency, Queen Elizabeth Hospital, Woolwich, London, UK; ${ }^{3}$ Accident and Emergency, Chiaring Cross Hospital, London, UKi ${ }^{4}$ Paediatric Infectious Disease, St George's Hospital, London, UK; ${ }^{5}$ Paediatric Infectious Disease Research Group, St George's University of London, UK

\subsection{6/archdischild-2018-rcpch.319}

Introduction Since 2015, an outbreak of Zika Virus infection $(\mathrm{ZiKV})$ has been reported in over 30 countries. Emerging evidence suggest ZikV causes a spectrum of neurologic diseases both directly and by secondary autoimmunity. In pregnancy, $\mathrm{ZiKV}$ is a well-known cause of congenital brain abnormalities, including microcephally, and has been linked with GuillainBarre syndrome. However, its association with seizures in children is not well described.

Methods We undertook a systematic review of the English literature published from 1947 to August 2017 to evaluate the risk factors, epidemiology, clinical presentation, management and outcomes of seizure following Zika virus infection in children less than 18 years. Data sources included MEDLINE, EMBASE, Cochrane library, and references within identified articles. We also searched the papers using the ISI web of knowledge, to identify relevant articles and conference proceedings.

Results We identified 140 potential studies, of which 8 were duplicate and 122 were excluded on the basis of title and abstracts. A further 2 additional studies did not meet eligibility criteria. Of the 8 eligible studies [3-10], there were 215 with confirmed $\mathrm{ZiKV}$ in children less than 18 years by either RTPCR in plasma, CSF and urine, EEG and MRI while excluding other etiologies. 20\% $(n=44)$ cases of had seizure. Among 5 studies reporting clinical characteristics and outcome, the mean age was 5 months (Range 1-8 months) and $75 \%$ $(n=12 / 16)$ of cases were female. All had abnormal neuroimaging $(n=44)$ and responded to anti-convulsant therapy, with no reported mortality.

Conclusions and clinical implications Complications from $\mathrm{ZiKV}$, although uncommon, may be severe. With international spread, clinicians need to be aware that ZiKV may be associated with seizures in children. Therefore, standardising the collection and reporting for individual cases across regions and countries would further allow meaningful analysis of the data collected, enabling monitoring of trends over time.

\section{Association of Paediatric Emergency Medicine}

\section{G330 THE PREVIEW TRIAL - A PROSPECTIVE, RANDOMISED, DOUBLE-BLIND, PLACEBO CONTROLLED TRIAL ASSESSING ORAL PREDNISOLONE IN PRE-SCHOOL AGED CHILDREN WITH VIRAL ASSOCIATED WHEEZE}

${ }^{1} \mathrm{SJ}$ Foster, ${ }^{2} \mathrm{MN}$ Cooper, ${ }^{1} \mathrm{~S}$ Oosterhof, ${ }^{1,3} \mathrm{ML}$ Borland. 'Paediatric Emergency Department, Princess Margaret Hospital for Children, Perth, Western Australia, Australia; ${ }^{2}$ Telethon Kids Institute, The University of Western Australia, Perth, Australia; ${ }^{3}$ Divisions of Paediatrics and Emergency Medicine, School of Medicine, University of Western Australia, Perth, Australia

\subsection{6/archdischild-2018-rcpch.320}

Background Pre-school aged children experience frequent episodes of wheeze that follow a different clinical course to 